\title{
EFFECTS OF ALUMINIUM TOXICITY ON ROOT AND SHOOT GROWTH OF RICE AND CHICKPEA SEEDLINGS
}

\author{
Rifat Samad*, Parveen Rashid and JL Karmoker \\ Department of Botany, University of Dhaka, Dhaka-1000, Bangladesh
}

Keywords: Aluminium toxicity, Growth, Rhizobox, Rice, Chickpea

\begin{abstract}
Increasing concentrations of aluminium progressively declined primary root length and number of lateral roots in rice and chickpea seedlings grown in rhizobox. It also inhibited the root and shoot length, dry weight of root and shoot of rice and chickpea seedlings grown in solution culture. On the other hand, it enhanced shoot/root length ratio and dry weight ratio for both the genera.
\end{abstract}

\section{Introduction}

Free aluminium ions were reported to be the main factor for inhibiting root growth of plants grown in acidic soils (Matsumoto 2000, Ma 2007). Root growth inhibition is the most evident symptom of Al toxicity which can be detected within $30 \mathrm{~min}$ to $2 \mathrm{hrs}$, even at micromolar concentrations of $\mathrm{Al}$ (Barceló and Poschenrieder 2002). $\mathrm{AlCl}_{3}(50 \mu \mathrm{M})$ at $\mathrm{pH} 4.5$ inhibited root growth by $65 \%$ in wheat and by $25-50 \%$ in oil seed rape and oat (Zheng et al. 1998).

Aluminium toxicity adversely affected plant growth in many plants (Gupta et al. 2013, Karimaei and Poozesh 2016). The changes in the root and shoot length of Vigna radiata showed a gradual decrease with the increase in aluminium oxide $\left(\mathrm{Al}_{2} \mathrm{O}_{3}\right)$ from 200 to $1000 \mathrm{ppm}$ (Mahapatra et al. 2015).

Rice and chickpea were used as plant materials because reports on the effects of aluminium toxicity on root elongation and plant growth of these two genera are rare. Hence, the present study aimed to assess the influence of aluminium ${ }^{3+}$ stress on root elongation, number of lateral roots, root and shoot growth of rice and chickpea grown in rhizobox and solution culture.

\section{Materials and Methods}

Rice (Oryza sativa L. var. BRRI Dhan-53) seeds were obtained from Bangladesh Rice Research Institute (BRRI) and that of chickpea (Cicer arietinum L. var. BARI Chhola-7) from Bangladesh Agricultural Research Institute (BARI), respectively.

In order to study the root elongation and number of lateral roots starting from germination of seeds, rice and chickpea seedlings were raised in rhizobox (Plates 1 and 2) as described by Marschner and Römheld (1983). Surface sterilized rice and chickpea seeds were germinated on moist filter paper placed in Petridish at a temperature of $30 \pm 1{ }^{\circ} \mathrm{C}$ and $25 \pm 1{ }^{\circ} \mathrm{C}$, respectively (Samad and Karmoker 2013). The sprouting was considered as the zero hour of age of the seedling. A one-day-old seedling was placed in the rhizobox filled with quartz sand where the radical was in the sand while the plumule was protruding outside through the hole in rhizobox.

The sand of three rhizoboxes with seedlings were moistened with half strength Hoagland solution (Hoagland and Arnon 1950) which was used as control ( $\mathrm{pH} 4.2)$ and other nine rhizoboxes were moistened with 50,100 and $150 \mu \mathrm{M} \mathrm{AlCl}$ solution ( $\mathrm{pH} 4.2$ ). The length and number of lateral roots traced in the tracing paper was measured and recorded from the $1^{\text {st }}$ to $5^{\text {th }}$ day of germination.

\footnotetext{
*Author for correspondence: <rifatsamad@gmail.com>.
} 


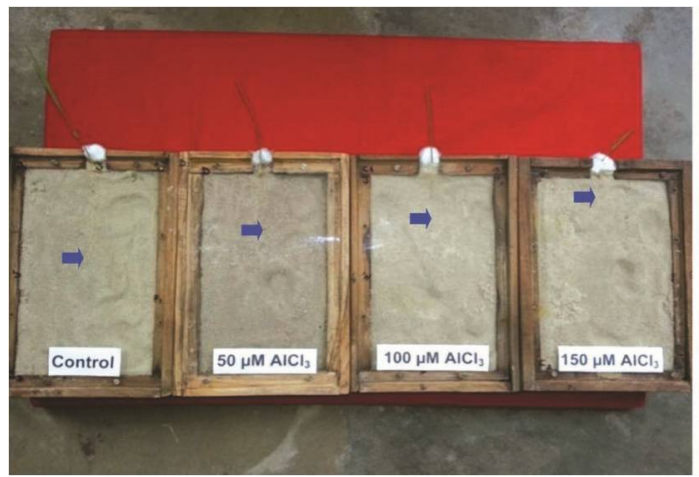

Plate 1. Effects of aluminium toxicity on the root growth of rice seedlings grown in rhizobox.

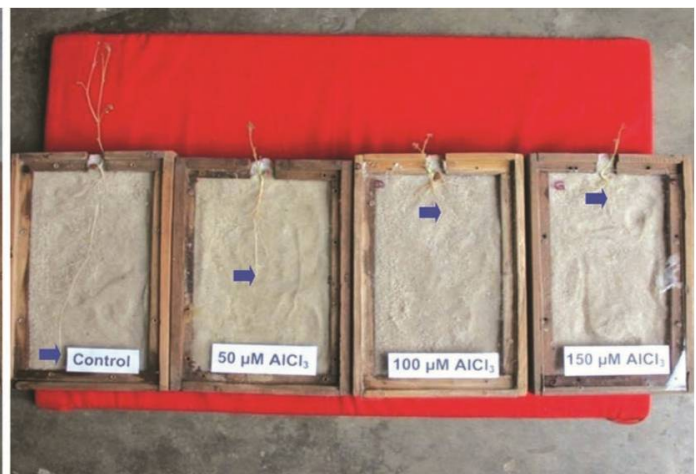

Plate 2. Effects of aluminium toxicity on the root growth of chickpea seedlings grown in rhizobox.

Surface sterilized rice and chikpea seeds were germinated in half strength Hoagland solution for $48 \mathrm{hrs}$. Then the germinated seeds were transferred to light bank. Rice seedlings were grown at a day/night temperature of $30^{\circ} \mathrm{C} \pm 1{ }^{\circ} \mathrm{C} / 25^{\circ} \mathrm{C} \pm 1^{\circ} \mathrm{C}$ and day/night length of $14 / 10 \mathrm{hrs}$. Chickpea seedlings were grown at a day/night temperature of $25^{\circ} \mathrm{C} \pm 1{ }^{\circ} \mathrm{C} / 18^{\circ} \mathrm{C} \pm 1^{\circ} \mathrm{C}$ and day/night length of $10 \mathrm{~h} / 14 \mathrm{hrs}$. Light intensity was $160 \mu$-einstein $\mathrm{m}^{-2} \mathrm{~s}^{-1}$. The solution was replenished every 48 hrs. The solution was continuously aerated through bubbler with the help of air compressor (Hoagland and Arnon 1950). Seven-day-old seedlings were transferred to half strength Hoagland

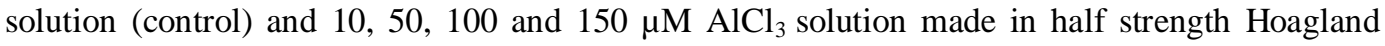
solution. The $\mathrm{pH}$ of all solutions including control were adjusted to 4.2 with $0.2 \mathrm{~N} \mathrm{H}_{2} \mathrm{SO}_{4}$. Length of root and shoot of the seedlings were measured in $\mathrm{cm}$ with a scale at 3, 6, 24, 48, 72 and $96 \mathrm{hrs}$ of aluminium treatment.

The root and shoot samples were collected and dried in an oven at $75^{\circ} \mathrm{C}$ for 72 hrs to a constant weight. Dry weights of the samples were recorded with an electronic balance. Data obtained in this investigation was analyzed statistically (Steel et al. 1997).

\section{Results and Discussion}

$\mathrm{AlCl}_{3}(50 \mu \mathrm{M})$ decreased primary root length of rice by 24.4 to $59.0 \%$ from 1 to 5 day of treatment. Similarly, $150 \mu \mathrm{M} \mathrm{AlCl}{ }_{3}$ caused a 31.7 to $70 \%$ inhibition of primary root length of rice from 1 to 5 day of application (Fig. 1). In chickpea seedlings, exposure to 100 and $150 \mu \mathrm{M} \mathrm{AlCl}_{3}$ resulted in 64.5 to $82.6 \%$ and 66.0 to $83.0 \%$ inhibition of primary root length of chickpea, respectively, from 1 to 5 day of treatment (Fig. 2). $\mathrm{AlCl}_{3}(50 \mu \mathrm{M})$ decreased the number of lateral roots of rice from 50.0 to $48.0 \%$ from 1 to 5 day of treatment. Similar magnitude of inhibition of the number of lateral roots of rice was recorded at $150 \mu \mathrm{M} \mathrm{AlCl}_{3}$ application (Fig. 3). In chickpea seedlings, $\mathrm{AlCl}_{3}(100 \mu \mathrm{M})$ caused an inhibition of the number of lateral roots by 80.0 to $77.0 \%$ from 2 to 5 day of treatment (Fig. 4). Similarly, Meda and Furlani (2005) found that $\mathrm{Al}^{3+}$ reduced the root elongation by $50 \%$ in tropical leguminous plant. Ryan et al. (1993) showed that $20 \mu \mathrm{M}$ $\mathrm{AlCl}_{3}$ inhibited root elongation of corn root by $50.0 \%$. Decrease in the number of lateral roots would decrease the ion absorption area of the root system.

The root length decreased with the increase in $\mathrm{AlCl}_{3}$ concentration from 10 to $150 \mu \mathrm{M}$. The highest inhibition from 43.4 to $61.6 \%$ of the root length was exerted by $150 \mu \mathrm{M} \mathrm{AlCl}_{3}$ over a period of 3 to $96 \mathrm{hrs}$ of treatment (Fig. 5a). $\mathrm{AlCl}_{3}(50 \mu \mathrm{M})$ decreased the shoot length of rice by 8.8 to $22.3 \%$ from 3 to $96 \mathrm{hrs}$ of treatment (Fig. 5b). On the other hand, aluminium, at a 
concentration of $10 \mu \mathrm{M}$, increased shoot/root length ratio of rice by 14.2 to $47.2 \%$ from 3 to $96 \mathrm{~h}$ of treatment. The maximum stimulation of shoot/root length ratio was recorded at $150 \mu \mathrm{M} \mathrm{AlCl}_{3}$ which ranged from 45.8 to $76.4 \%$ from 3 to $96 \mathrm{hrs}$ of application (Fig. 5c).

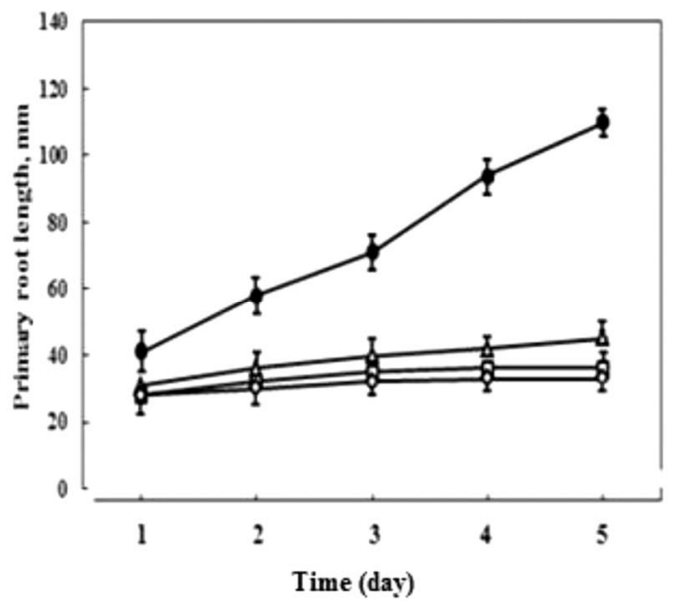

Fig. 1. Effects of different concentrations of aluminium on the primary root length of rice seedlings grown in rhizobox. • represents control; $\Delta 50 \mu \mathrm{M} \mathrm{Al} ; \square 100 \mu \mathrm{M}$ $\mathrm{Al} ; \diamond 150 \mu \mathrm{M} \mathrm{Al}$. Each value is the mean of three replicates \pm standard error.

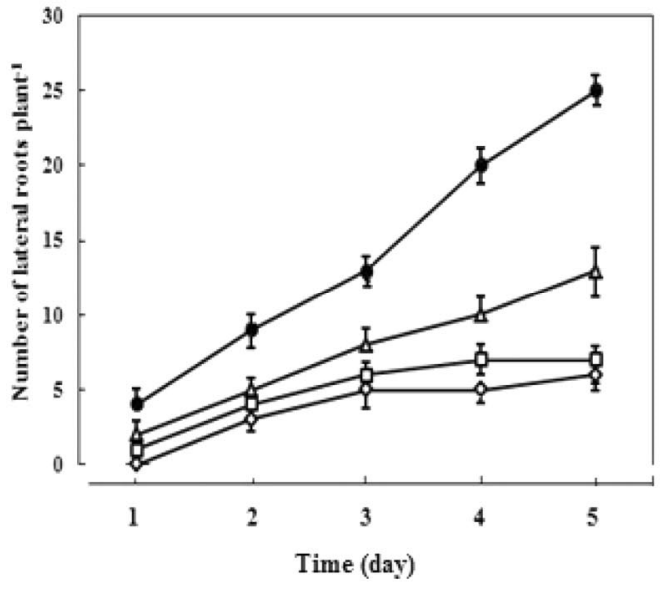

Fig. 3. Effects of different concentrations of aluminium on the number of lateral roots of rice seedlings grown in rhizobox. Otherwise as Fig. 1.

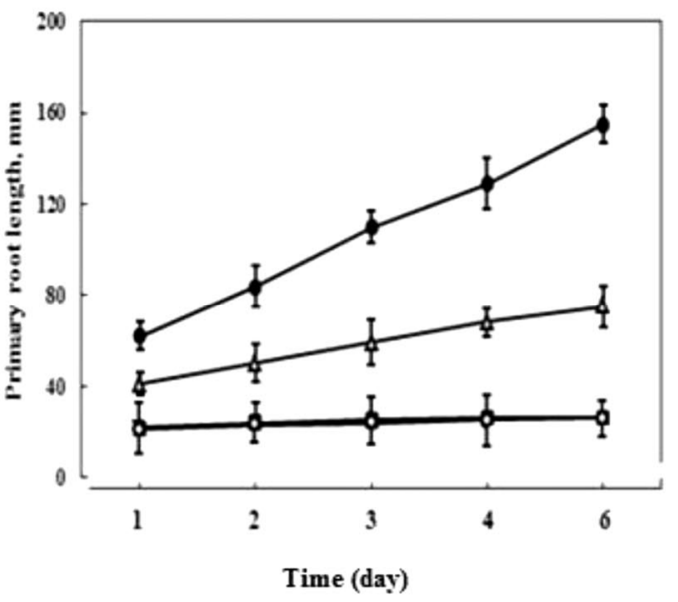

Fig. 2. Effects of different concentrations of aluminium on primary root length of chickpea seedlings grown in rhizobox. Otherwise as Fig. 1.

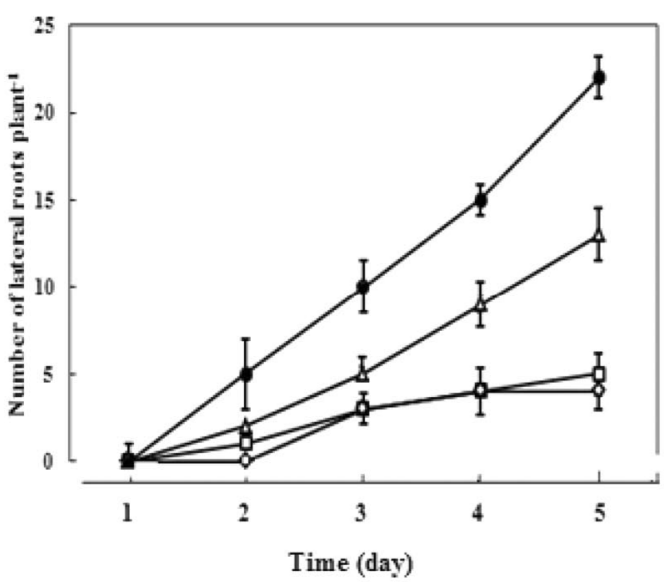

Fig. 4. Effects of different concentrations of aluminium on the number of lateral roots of chickpea seedlings grown in rhizobox. Otherwise as Fig. 1.

In chickpea seedlings, $50 \mu \mathrm{M} \mathrm{AlCl}{ }_{3}$ decreased the root length by 7.3 to $41.6 \%$ from 3 to 96 hrs of treatment (Fig. 6a). $\mathrm{AlCl}_{3}$, at a concentration of $100 \mu \mathrm{M}$, decreased the shoot length of chickpea by 9.0 to $28.8 \%$ from 6 to 96 hrs of treatment (Fig. 6b). On the contrary, the shoot/root length of chickpea seedlings was found to increase by all the concentrations of $\mathrm{Al}(10-150 \mu \mathrm{M})$ 
used. 100 and $150 \mu \mathrm{M} \mathrm{AlCl}_{3}$ increased the shoot/root length by 19.9 to $48.0 \%$ and 31.9 to $65.0 \%$, respectively, from 3 to $96 \mathrm{hrs}$ of treatment (Fig. 6c).
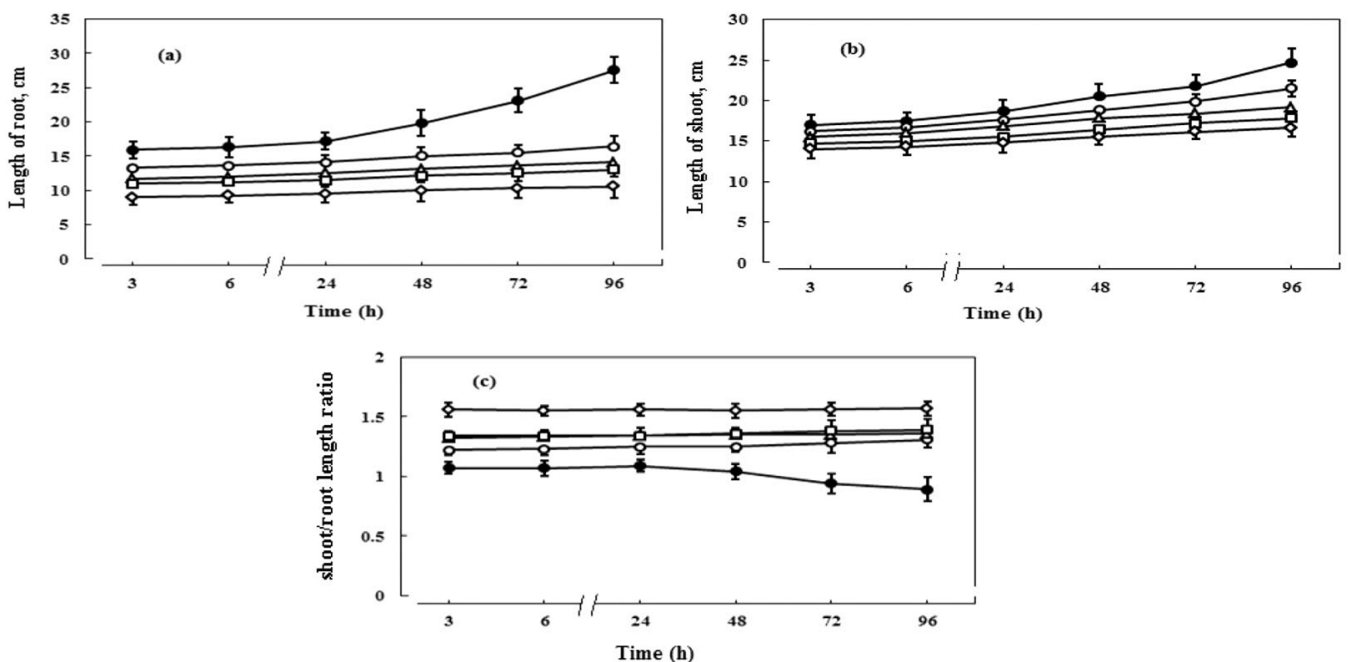

Fig. 5. Effects of different concentrations of aluminium on the (a) root length, (b) shoot length and (c) shoot/root length ratio of rice seedlings grown in solution culture. $\bullet$ represents control; $\diamond 10 \mu \mathrm{M} \mathrm{Al} ; \Delta 50 \mu \mathrm{M} \mathrm{Al} ; \square 100 \mu \mathrm{M} \mathrm{Al} ; \diamond$ $150 \mu \mathrm{M} \mathrm{Al}$. Each value is the mean of three replicates \pm standard error.
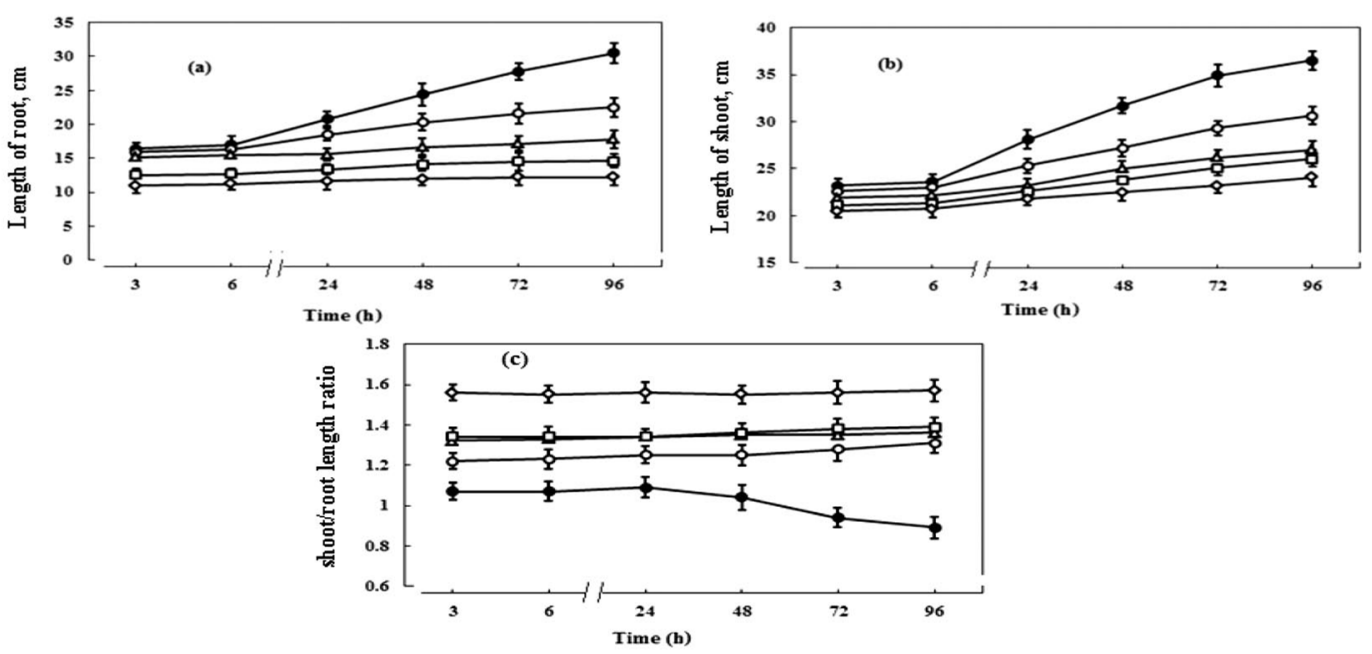

Fig. 6. Effects of different concentrations of aluminium on the (a) root length, (b) shoot length and (c) shoot/root length ratio of chickpea seedlings grown in solution culture. Otherwise as Fig. 5.

$\mathrm{AlCl}_{3}(10-150 \mu \mathrm{M})$ decreased the length of rice and chickpea seedlings (Plates 3 and 4). The maximum inhibition of length of rice seedlings was observed at $150 \mu \mathrm{M} \mathrm{AlCl}_{3}$ which ranged from 30.1 to $48.0 \%$ from 3 to $96 \mathrm{hrs}$ of application (Table 1). Similarly, $\mathrm{AlCl}_{3}(10$ and $150 \mu \mathrm{M}$ ) decreased the length of chickpea seedlings. $100 \mu \mathrm{M} \mathrm{AlCl} 3$ inhibited the length of chickpea seedlings by 15.2 to $39.4 \%$ from 3 to 96 hrs of exposure (Table 2 ). 


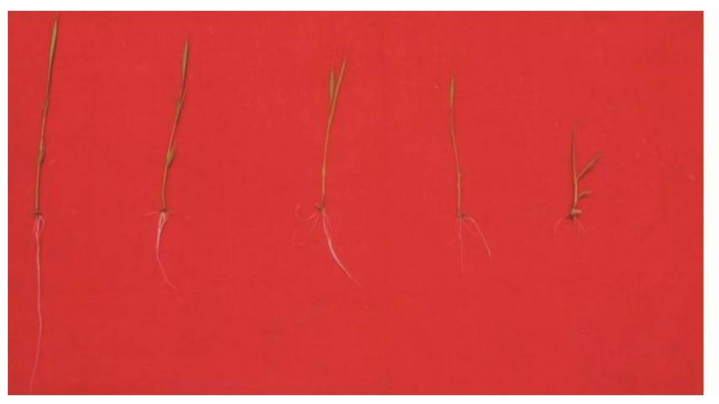

Plate 3. Effects of aluminium toxicity on the root and shoot length of rice seedlings grown in solution culture.

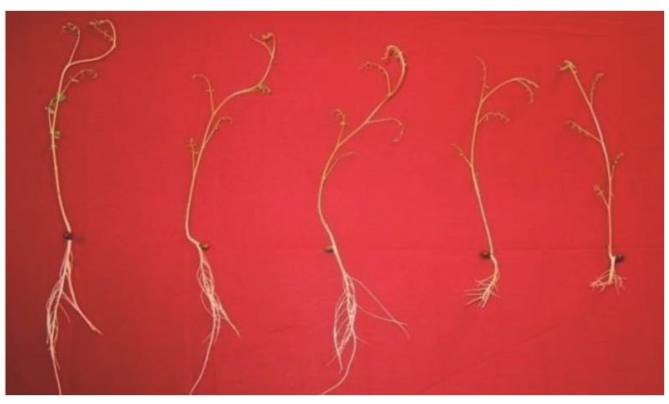

Plate 4. Effects of aluminium toxicity on the root and shoot length of chickpea seedlings grown in solution culture.

Table 1. Effects of different concentrations of aluminium on the length of rice seedlings grown in solution culture. Each value is the mean of three replicates \pm standard error.

\begin{tabular}{lcccccc}
\hline & \multicolumn{5}{c}{ Length of seedling $(\mathrm{cm})$} \\
\cline { 2 - 6 } Treatment & 03 & 06 & 24 & 48 & 72 & 96 \\
\cline { 2 - 6 } & 32.9 & 33.8 & 35.9 & 40.3 & 44.9 & 52.3 \\
Control & \pm 0.186 & \pm 0.250 & \pm 0.246 & \pm 0.295 & \pm 0.273 & \pm 0.326 \\
& 29.5 & 30.3 & 31.7 & 33.8 & 35.4 & 37.9 \\
$10 \mu \mathrm{M} \mathrm{AlCl}$ & \pm 0.221 & \pm 0.189 & \pm 0.167 & \pm 0.141 & \pm 0.124 & \pm 0.278 \\
& 27.2 & 28.0 & 29.3 & 30.9 & 32.0 & 33.3 \\
$50 \mu \mathrm{M} \mathrm{AlCl}_{3}$ & \pm 0.282 & \pm 0.291 & \pm 0.152 & \pm 0.138 & \pm 0.158 & \pm 0.130 \\
& 25.7 & 26.2 & 27.0 & 28.7 & 29.7 & 30.8 \\
$100 \mu \mathrm{M} \mathrm{AlCl}_{3}$ & \pm 0.190 & \pm 0.317 & \pm 0.171 & \pm 0.127 & \pm 0.135 & \pm 0.242 \\
& 23.0 & 23.5 & 24.3 & 25.5 & 26.4 & 27.2 \\
$150 \mu \mathrm{M} \mathrm{AlCl}_{3}$ & \pm 0.263 & \pm 0.232 & \pm 0.228 & \pm 0.276 & \pm 0.180 & \pm 0.317 \\
\hline
\end{tabular}

Table 2. Effects of different concentrations of aluminium on the length of chickpea seedlings grown in solution culture. Each value is the mean of three replicates \pm standard error.

\begin{tabular}{lcccccc}
\hline \multirow{3}{*}{ Treatment } & \multicolumn{5}{c}{ Length of seedling $(\mathrm{cm})$} \\
\cline { 2 - 6 } & 03 & 06 & 24 & 48 & 72 & 96 \\
\cline { 2 - 6 } & 39.6 & 40.6 & 48.9 & 56.1 & 62.7 & 67.0 \\
Control & \pm 0.164 & \pm 0.246 & \pm 0.175 & \pm 0.209 & \pm 0.159 & \pm 0.248 \\
& 38.5 & 39.3 & 43.8 & 47.5 & 50.9 & 53.1 \\
$10 \mu \mathrm{M} \mathrm{AlCl}$ & \pm 0.153 & \pm 0.196 & \pm 0.164 & \pm 0.251 & \pm 0.182 & \pm 0.146 \\
& 37.1 & 37.7 & 38.8 & 41.7 & 43.4 & 44.8 \\
$50 \mu \mathrm{M} \mathrm{AlCl}_{3}$ & \pm 0.140 & \pm 0.187 & \pm 0.172 & \pm 0.168 & \pm 0.154 & \pm 0.191 \\
& 33.6 & 34.0 & 36.0 & 37.9 & 39.6 & 40.6 \\
$100 \mu \mathrm{M} \mathrm{AlCl}_{3}$ & \pm 0.166 & \pm 0.179 & \pm 0.180 & \pm 0.173 & \pm 0.163 & \pm 0.184 \\
& 31.5 & 31.9 & 33.4 & 34.5 & 35.4 & 36.3 \\
$150 \mu \mathrm{M} \mathrm{AlCl}_{3}$ & \pm 0.171 & \pm 0.188 & \pm 0.157 & \pm 0.195 & \pm 0.220 & \pm 0.253 \\
\hline
\end{tabular}


Kinraide et al. (1985) reported that a $60 \%$ reduction in the root growth was observed in 2day-old Dayton barley exposed to less than $1 \mu \mathrm{M}$ Al. Mahapatra et al. (2015) found that $\mathrm{Al}$ decreased the root and shoot length of Vigna radiata.

Aluminium, at concentrations of 10 and $50 \mu \mathrm{M}$, decreased the dry weight of root of rice seedlings by 33.3 to $55.6 \%$ from 3 to $96 \mathrm{hrs}$ of treatment (Fig. 7a). In rice seedlings, a maximum of 40.0 to $44.5 \%$ inhibition in the shoot dry weight was observed following $150 \mu \mathrm{M} \mathrm{Al}$ treatment (Fig. 7b). On the contrary, $10 \mu \mathrm{M} \mathrm{Al}$ increased shoot/root dry weight ratio of rice by 20.0 to $40.0 \%$ from 3 to $96 \mathrm{hrs}$ of application (Fig. 7c).
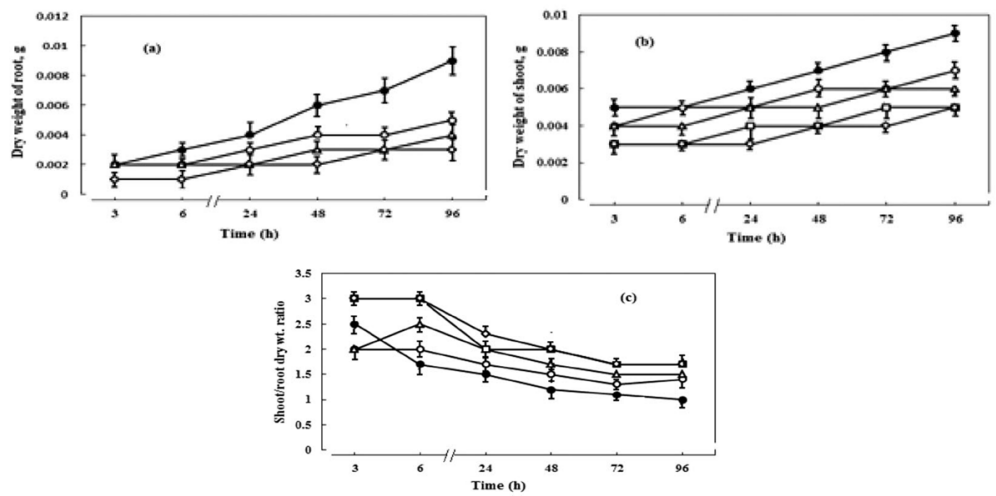

Fig. 7. Effects of different concentrations of aluminium on dry weight of the (a) root, (b) shoot and (c) shoot/root dry weight ratio of rice seedlings grown in solution culture. Otherwise as Fig. 5.
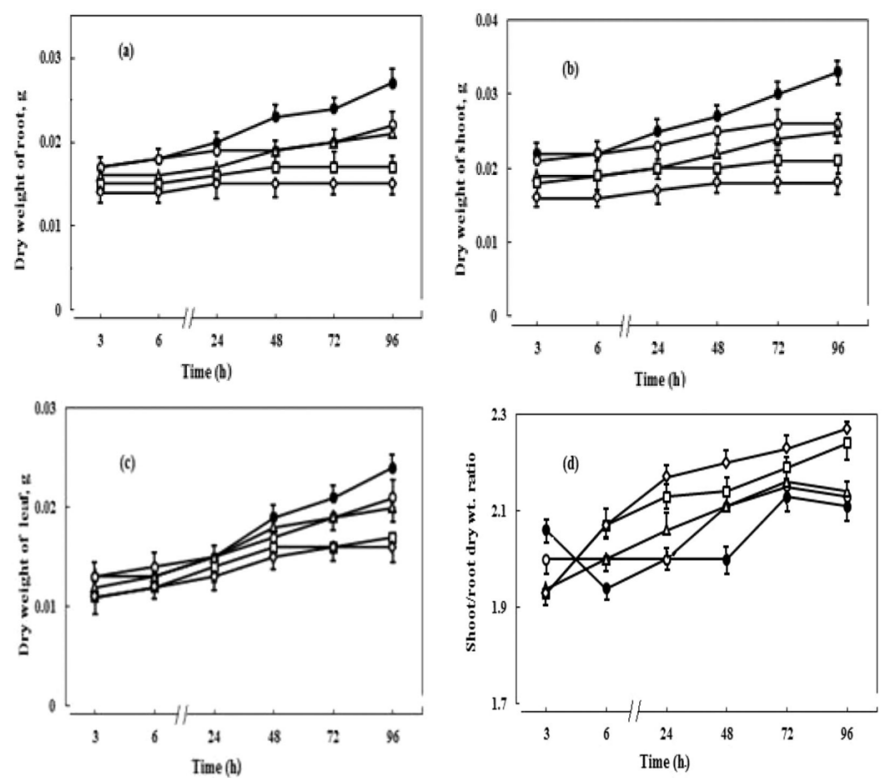

Fig. 8. Effects of different concentrations of aluminium on dry weight of the (a) root, (b) stem, (c) leaf and (d) shoot/root ratio of chickpea seedling grown in solution culture. Otherwise as Fig. 5.

Similarly, in chickpea seedlings, 100 and $150 \mu \mathrm{M}$ Al caused 11.8 to $44.4 \%$ inhibition of the root dry weight from 3 to 96 hrs of application (Fig. 8a). The dry weight of shoot of chickpea 
seedlings decreased gradually with the increase in $\mathrm{Al}$ concentrations from 10 to $150 \mu \mathrm{M}$. A maximum of 27.3 to $45.5 \%$ inhibition of the dry weight of stem was recorded at $150 \mu \mathrm{M} \mathrm{Al}$ at 3 to 96 hrs of treatment (Fig. 8b).

In chickpea, the maximum stimulation of shoot/root dry weight ratio was observed following $150 \mu \mathrm{M} \mathrm{Al}$ treatment which ranged from 6.3 to $12.4 \%$ over a exposure period of $96 \mathrm{hrs}$ (Fig. 8d). Similarly, Al decreased the dry weight of cultured cells of tobacco (Abdel-Basset et al. 2013). On the contrary, Symeonidis et al. (2004) found that Al increased the dry weight of melon (Cucumis melo).

Aluminium stress induced decrease in primary root length and number of lateral roots in rice and chickpea seedlings and inhibition of long term root growth cause a decrease in root surface area. The decrease in root surface area would lead to a decrease in absorption of ions.

\section{References}

Abdel-Basset R, Ozuka S, Demiral T, Furuichi T, Sawatani I, Baskin TI, Matsumoto H and Yamamoto Y 2013. Aluminium reduces sugar uptake in tobacco cell cultures: a potential cause of inhibited elongation but not of toxicity. J. Exp. Bot. 61: 1597-1610.

Barceló J and Poschenrieder C 2002. Fast root growth responses, root exudates, and internal detoxification as clues to the mechanisms of aluminium toxicity and resistance: a review. Environ. Exp. Bot. 48: 75-92.

Gupta N, Gaurav SS and Kumar A 2013. Molecular basis of aluminium toxicity in plants: A review. American J. Plant Sci. 4: 21-37.

Hoagland DR and Arnon DI 1950. The water culture method for growing plants without soils. Berkeley: California Agricultural Experimental Station, pp. 347.

Karimaei M and Poozesh V 2016. Effects of aluminium toxicity on plant height, total chlorophyll (chl. a+b), potassium and calcium contents in spinach (Spinacia oleracea L.). Int. J. Farm. Allied Sci. 5: 76-82.

Kinraide TB, Arnold RC and Baligar VC 1985. A rapid assay for aluminium phytotoxicity at submicromolar concentrations, Physiol. Plant. 65: 245-250.

Ma JF 2007. Syndrome of aluminium toxicity and diversity of aluminium resistance in higher plants. Int. Rev. Cytol. 264: 225-252.

Mahapatra M, Sabat G, Patro L, Padhy R and Mohanty BK 2015. Studies of aluminum $\left(\mathrm{Al}_{2} \mathrm{O}_{3}\right)$ stress on morphology and pigments of Vigna radiata L. Int. J. Adv. Res. Biol. Sci. 2: 173-177.

Marschner H and Römheld V 1983. In vivo measurement of root-induced $\mathrm{pH}$ changes at the soil-root interface: Effect of plant species and nitrogen source. Z. für Pflanzenphysiologie 111: 241-251.

Matsumoto H 2000. Cell biology of aluminium toxicity and tolerance in higher plants. Int. Rev. Cytol. 200: $1-46$.

Meda AR and Furlani PR 2005. Tolerance to aluminium toxicity by tropical leguminous plants used as cover crops. Braz. Arch. Biol. Technol. 48: 309-317.

Ryan PR., Di Tomaso, JM and Kochian LV 1993. Aluminium toxicity in roots: an investigation of spatial sensitivity and the role of the root cap. J. Exp. Bot. 44: 437-446.

Samad R and Karmoker JL 2013. Effects of $\mathrm{NaCl}$ salinity stress on accumulation of $\mathrm{K}^{+}, \mathrm{Na}^{+}, \mathrm{Cl}^{-}, \mathrm{NO}_{3}^{-}$, sugar and proline contents in the seedlings of Triticale-I. Bangladesh J. Bot. 42: 189-194.

Steel RGD, Torrie JH and Dickey DA 1997. Principles and procedures of statistics. McGraw Hill Book Co. Inc., New York. Pp. 666.

Symeonidis L, Abou-Auda MMA and Yupsanis P 2004. Aluminium toxicity effects on Cucumis melo and response of diphosphonucleoside kinases. Biol. Bratis. 59: 133-139.

Zheng SJ, Ma JF and Matsumoto H 1998. Continuous secretion of organic acid is related to aluminium resistance in relatively long-term exposure to aluminium stress. Physiol. Plant. 103: 209-214. 